\title{
Fan-on-Face Therapy in Relieving Dyspnea of Adult Terminally III Cancer Patients: A Meta-Analysis
}

\author{
Marvin Jonne L. Mendoza', $\quad$ Frederic Ivan L. Ting1, $\odot \quad$ John Paulo B. Vergara ${ }^{1, \odot}$ \\ Danielle Benedict L. Sacdalan ${ }^{1,2, \odot}$ Jennifer Sandoval-Tan ${ }^{1, \odot}$
}

${ }^{1}$ Division of Medical Oncology, Department of Medicine, Philippine General Hospital and University of the Philippines, Manila, Philippines

${ }^{2}$ Department of Pharmacology and Toxicology, College of Medicine, University of the Philippines, Manila, Philippines

Asian J Oncol 2020;6:88-93

\begin{abstract}
Address for correspondence Frederic Ivan L. Ting, MD, Division of Medical Oncology, Department of Medicine, Philippine General Hospital and University of the Philippines, Manila 1000, Philippines (e-mail: fredtingmd@gmail.com).
\end{abstract}

Abstract

\section{Keywords}

- fan-on-face therapy

- fan therapy

- dyspnea

- dyspnea score

- terminally ill cancer patients

- meta-analysis
Introduction Dyspnea is often encountered in terminally ill cancer patients and is attributed to multiple factors. The use of fan-on-face therapy is a nonpharmacologic adjunct treatment for adult cancer patients suffering from dyspnea at the end-of-life. This study was done to determine if the use of fan-on-face therapy in addition to the standard of care treatment indeed confers clinical benefit to terminally ill adult cancer patients with dyspnea.

Materials and Methods A meta-analysis of randomized controlled trials on the use of fan-on-face therapy in relieving dyspnea among terminally ill adult cancer patients was performed. A computerized search was done in MEDLINE, NICE, CENTRAL, Science Direct, and Google Scholar for relevant articles. Other publications were searched, and authors were contacted for additional information. The primary outcome measure was the mean change in dyspnea score, determined by the Modified Borg Scale, Numeric Rating Scale, or Visual Analog Scale. The secondary outcome was the post-intervention mean change in respiratory rate (RR).

Results Four eligible randomized controlled trials of low to moderate risk of bias employed a total of 139 cancer patients. Fan-on-face therapy was effective in decreasing mean dyspnea scores (standard mean difference $=-1.81,95 \%$ confidence interval $[\mathrm{Cl}]:-3.12,-0.50, p<0.00001, R^{2} 93 \%$ ) and improving mean change in RR (mean difference $=-0.91,95 \% \mathrm{Cl}:-1.68,-0.15 ; p=0.001, I^{2}=81 \%$ ) versus control.

Conclusion Fan-on-face therapy, as an adjunct to standard of care, is effective in alleviating dyspnea among adult cancer patients during the end of life.

\section{Introduction}

Dyspnea is a distressing symptom often experienced by patients with advanced cancer and has multifactorial causes. ${ }^{1}$ It negatively affects the patient's physical, psychological, and emotional well-being. Furthermore, it causes a great deal of anxiety for their relatives and caregivers, thus a need for its effective management.
Among patients with terminally ill cancer, the symptom of breathlessness has many causes. It may be tumor-related (e.g., cancer-induced airway obstruction), from complications related to the malignant condition (e.g., anemia, malignant effusion), or associated with the patient's comorbid conditions (e.g., chronic obstructive pulmonary disease, asthma). With careful regard to a cancer patient's overall condition and the stage of disease,
DOI https://doi.org/

$10.1055 / \mathrm{s}-0040-1713332$

ISSN 2454-6798.
License terms

(ㅇ) (1) $\ominus \circledast$ 
symptom-directed therapeutic options should always be considered and discussed with the patient and the family. ${ }^{1}$ At the end-of-life, the primary goals shift from cure to alleviation of distressing symptoms, provision of comfort, and enhancing the quality of life.

In managing dyspnea, strategies include both pharmacologic and nonpharmacologic interventions. Pharmacologic interventions are guided by the underlying comorbidities and include bronchodilators, nebulized saline, corticosteroids, diuretics, atypical antipsychotics, opioids, anxiolytics, or a combination of any of these. ${ }^{2}$ However, a study also showed that drug therapy was not completely effective in relieving dyspnea in patients with advanced cancer. ${ }^{3}$

Nonpharmacologic interventions on the other hand include cognitive behavioral therapy, coping and adaptation strategies, neuromuscular electrical stimulation, acupuncture, and fan-on-face therapy. These strategies are diverse and cover the gamut of supportive care disciplines and serve as adjuncts to pharmacologic interventions. Moreover, these interventions may require specialist training to properly administer. ${ }^{4,5}$ In this context, fan-on-face therapy stands out due to its ease of performance, lowcost, and minimal side effect.

In fan-on-face therapy, the air from a motorized fan is directed to the face or cheeks to relieve symptoms of breathlessness. ${ }^{6}$ There is substantial variability in the way patients use fan-on-face therapy vis-à-vis other management strategies. Moreover, there is no established flow rate, timing, frequency, duration, positioning, and location of use. Despite these, studies have supported its effectiveness in reducing dyspnea. ${ }^{7,8}$

Here we present the results of an updated systematic review and meta-analysis of clinical trial data on the use of fan-on-face therapy as an adjunct to standard therapy to relieve dyspnea in terminally ill adult cancer patients. ${ }^{9}$ The mean change in self-reported dyspnea score was used to measure its clinical impact. Mean change in respiratory rate (RR), an objective parameter of improved breathing and adequate ventilation, was also taken into consideration as a surrogate for fan-on-face therapy's potential physiologic benefits.

\section{Materials and Methods}

A systematic review was conducted to identify studies on the benefit of fan-on-face therapy as an adjunct intervention in the management of dyspnea of terminally ill adult cancer patients. A computerized search for relevant published and unpublished articles was performed in MEDLINE, NICE, CENTRAL, Science Direct, and Google Scholar. A search in clinical registries (clinicaltrials.gov and Cochrane Central) for ongoing trials was also conducted. Search structures, subject headings, and keywords were tailored to each search database. The search terms included the following: fan-on-face therapy, fan therapy, dyspnea, dyspnea score, cancer, terminally ill cancer patients, and randomized controlled trials. The last search was updated last March 12, 2020. For clarifications of existing and/or missing data corresponding authors listed in eligible studies were contacted by electronic mail.

Five reviewers screened all citations, titles, and abstracts independently. Included studies were randomized controlled trials involving fan-on-face therapy versus placebo or any other interventions in the management of dyspnea of terminally ill adult cancer patients, with dyspnea score and $\mathrm{RR}$ assessment before and after intervention, were included for review. Excluded studies were any of the following: (1) indexed papers such as reviews, letters, commentaries, case reports/series, and expert opinions, (2) pediatric patients (age 17 years old and below), (3) other terminal conditions without malignancy, (4) studies with incomplete data, and (5) non-English language publications that do not have an English translation available.

Five investigators independently extracted data on the mean change in dyspnea score and mean change in RR of patients from the included studies using a data collection form from Cochrane. Risks of bias were independently assessed without blinding to authorship or journal by using the Cochrane risk of bias tool. Conflicts or discrepancies were resolved by consensus among the five investigators.

All tests were analyzed using Review Manager 5.3 (The Nordic Cochrane Centre, Copenhagen, Denmark). Continuous data were expressed as standard mean difference for the mean change in dyspnea score and weighted mean difference for the mean change in RR. Analysis of pooled outcomes employed the random effects analysis model. A $p$-value of $<0.05$ was used to ascertain statistical significance.

\section{Results}

\section{Description of Studies}

The characteristics of the included studies are summarized in - Table 1. These studies were four randomized controlled trials from Indonesia, China, Japan, and Philippines. The primary outcome considered was the mean change in dyspnea score, determined by the Modified Borg Scale, Numeric Scale, or Visual Analog Scale. The secondary outcome determined was the mean change in RR. All four randomized controlled trials employed a total of 139 terminally ill adult cancer patients. Two studies ${ }^{10,11}$ had a crossover design after a wash-out period of 1 hour. Lung cancer was the most common malignancy, and a great majority were provided with supplemental oxygen. All studies assessed outcomes after 5 minutes of providing fan-on-face therapy or placebo. Two studies used fan-on-legs as the comparison arm. ${ }^{11,12}$

\section{Results of the Search}

A total of 164 records from all searches were identified and subsequently, three duplicates were excluded. After 
Table 1 Characteristics of included studies

\begin{tabular}{|c|c|c|c|c|}
\hline Parameters & Puspawati et al $2017^{10}$ & Wong et al $2017^{21}$ & Kako et al $2018^{12}$ & Ting et al $2019^{11}$ \\
\hline Country & Indonesia & China & Japan & Philippines \\
\hline Setting & Hospital & Hospital & Hospital & Hospital \\
\hline Research design & $\begin{array}{l}\text { Open, randomized, } \\
\text { controlled, crossover trial }\end{array}$ & $\begin{array}{l}\text { Randomized, controlled } \\
\text { trial }\end{array}$ & $\begin{array}{l}\text { Parallel-arm, } \\
\text { randomized, controlled } \\
\text { trial }\end{array}$ & $\begin{array}{l}\text { Open, randomized, } \\
\text { placebo-controlled } \\
\text { crossover trial }\end{array}$ \\
\hline Blinding & Not possible & Not possible & Not possible & Not possible \\
\hline Population $(N)$ & 21 & 30 & 40 & 48 \\
\hline Mean age $(y)$ & 54 & No data & 69 & 51 \\
\hline $\begin{array}{l}\text { Duration of intervention } \\
\text { (min) }\end{array}$ & 5 & 5 & 5 & 5 \\
\hline Intervention & $\begin{array}{l}\text { Fan therapy } \\
\text { (Hand-held fan) }\end{array}$ & $\begin{array}{l}\text { Fan-on-face therapy } \\
\text { (electric desk fan) }\end{array}$ & $\begin{array}{l}\text { Fan-on-face therapy } \\
\text { (stand fan) }\end{array}$ & $\begin{array}{l}\text { Fan-on-face therapy } \\
\text { (stand fan) }\end{array}$ \\
\hline Comparison & $\begin{array}{l}\text { Diaphragmatic breathing } \\
\text { technique }\end{array}$ & $\begin{array}{l}\text { No fan, accompanied by } \\
\text { caregivers }\end{array}$ & $\begin{array}{l}\text { Fan-on-legs } \\
\text { (stand fan) }\end{array}$ & $\begin{array}{l}\text { Fan-on-legs } \\
\text { (stand fan) }\end{array}$ \\
\hline Outcome measures & $\begin{array}{l}\text { Mean change in dyspnea } \\
\text { score (Modified Borg } \\
\text { Scale) } \\
\text { Mean change in RR }\end{array}$ & $\begin{array}{l}\text { Mean change in dyspnea } \\
\text { score (verbal numerical } \\
\text { rating scale) } \\
\text { Mean change in RR }\end{array}$ & $\begin{array}{l}\text { Mean change in dyspnea } \\
\text { score (Numerical rating } \\
\text { scale) } \\
\text { Mean change in RR }\end{array}$ & $\begin{array}{l}\text { Mean change in dyspnea } \\
\text { score (Modified Borg } \\
\text { scale) } \\
\text { Mean change in RR }\end{array}$ \\
\hline
\end{tabular}

Abbreviation: RR, respiratory rate.

screening titles and abstracts, five full-text articles were assessed for eligibility. Of these, one study was excluded since data specific for cancer patients only could not be extracted. ${ }^{8}$ Finally, four full-text journals were eligible for inclusion. For the missing data of the study by Kako et al, ${ }^{9}$ the corresponding author was contacted and the raw data for pre- and post-intervention values of RR were provided. The flow of literature search is shown in $\boldsymbol{- F i g}$. 1 .

\section{Risk of Bias in Included Studies}

Risk of bias amongst the included studies is shown in -Fig. 2. There was poor reporting of methodological details. Two studies did not provide information on methods for randomization, while the implementation of allocation concealment was not described in three studies. Blinding of participants and personnel was difficult because of the nature of fan therapy. Follow-up among the studies were adequate.

\section{Effects of Interventions}

\section{Primary Outcome: Mean Change in Dyspnea Score}

All four RCTs demonstrated that fan-on-face therapy was effective in decreasing dyspnea scores. Pooled results showed statistically significant improvement in mean change in dyspnea score for the fan-on-face therapy arm (standard mean difference $=-1.81,95 \% \mathrm{CI}:-3.12,-0.50$; $\left.p<0.00001, I^{2}=93 \%\right)(-$ Fig. 3).

\section{Secondary Outcome: Mean Change in Respiratory Rate} Pooled analysis showed statistically significant improvement in mean change in $\mathrm{RR}$ (mean difference $=-0.91,95 \% \mathrm{CI}:-1.68$, $-0.15 ; p=0.001, I^{2}=81 \% ;-$ Fig. 4 ).

\section{Discussion}

This updated meta-analysis indicated that fan-on-face therapy, as an adjunct treatment, is an effective strategy in alleviating dyspnea in terminally ill adult cancer patients. Fan-on-face therapy significantly improved the mean change in dyspnea score which could be translated into clinical significance. The clinical benefit of dyspnea, measured as the minimum clinically important difference, is defined as a reduction of $\geq 1$ unit in any of the numerical rating scale. ${ }^{13,14}$ It is important to emphasize that dyspnea is a negative, subjective experience. ${ }^{15}$ Any improvement therefore in a patient's self-reported dyspnea score would translate significantly to their overall well-being and comfort.

Hypothesized physiological effects of fan-on-face therapy include direct stimulation of the face via cranial nerve $\mathrm{V}$ (trigeminal nerve), nasal mucosa, and the naso- and oropharyngeal apparatuses, and temperature cooling, all of which could potentially improve ventilation patterns. ${ }^{16-18}$ In contrast to the other recently published meta-analysis, which only looked into the effect of fan-on-face therapy on improvement in dyspnea score, this updated review attempted to look into potential physiologic improvements by fan-on-face therapy with the inclusion of mean change in RR as surrogate outcome. ${ }^{9}$ The present pooled analysis has shown significant improvement in mean change in RR. Admittedly, change in RR is potentially confounded by factors other than fan-on-face therapy such as the effect of opioids, which are commonly given in the palliative care of cancer patients. ${ }^{19}$

This study had several limitations. For all the included studies, the treatment duration was only 5 minutes. Moreover, the duration of relief afforded by this intervention was evanescent and varied from patient to patient. 


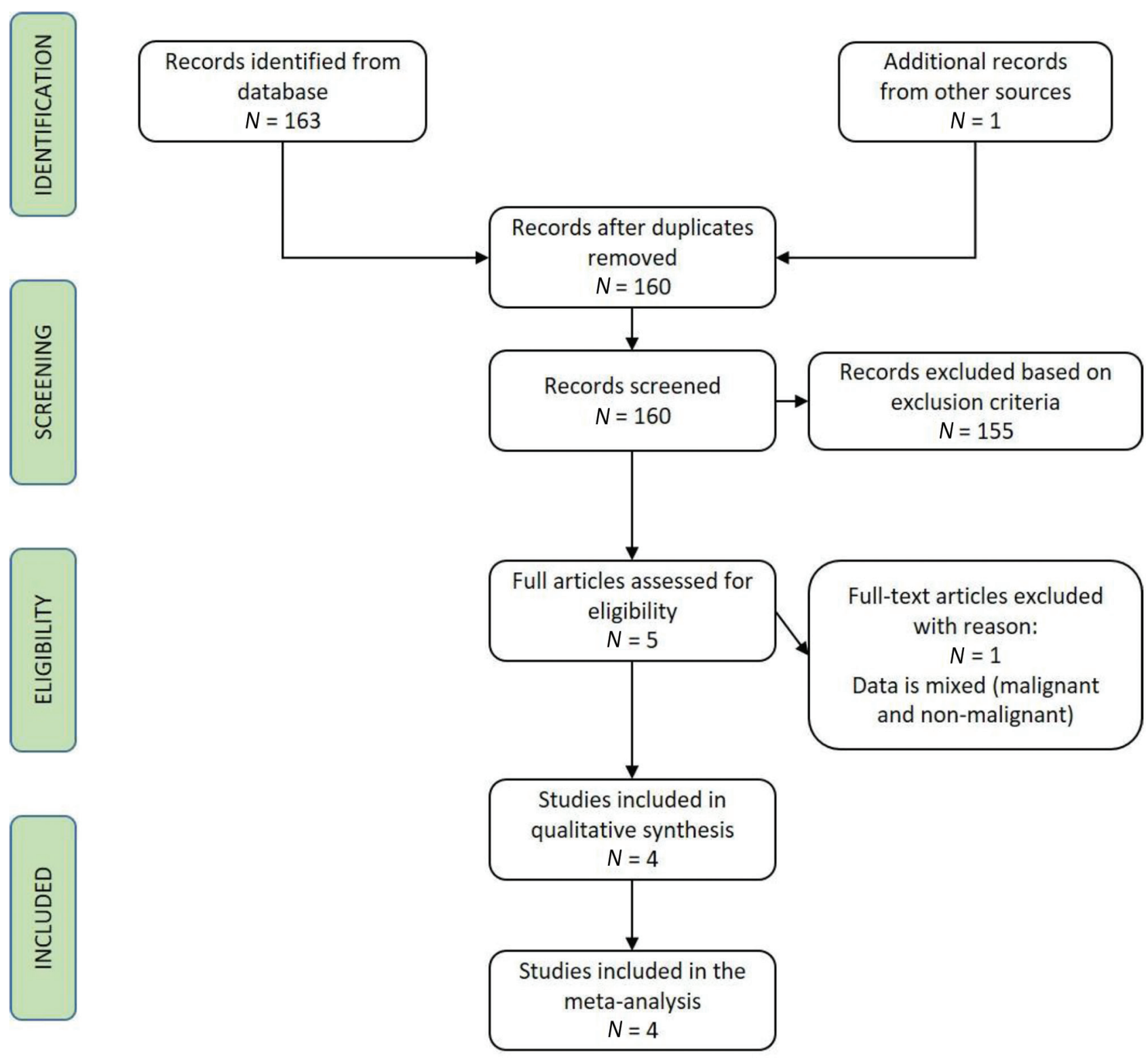

Fig. 1 Flow of literature search.

It is worth investigating if longer periods of fan-on-face therapy will afford longer periods of relief.

Publication bias could have been a major limitation since the selection of studies only included those which are published or can be translated into the English language. This meta-analysis included data from a local randomized controlled trial. ${ }^{11}$ The limited number of studies available for review is another concern.

Finally, it is unclear if fan-on-face therapy has an ideal method of administration. Questions such as an ideal fan for use or the ideal distance of patient from fan do not have clear answers. It is likely that for this intervention, no definite protocol will be defined but rather guidelines based on collective experience will be offered.

\section{Conclusion and Recommendation}

This updated meta-analysis was able to show a detailed comparison between fan-on-face therapy versus control as an adjunct treatment to standard of care in the alleviation of dyspnea. As for practicality and applicability, fanon-face therapy seems to be a favorable option for cancer patients at the end-of-life. By providing a steady airflow that cools down the surface temperature of the skin, fan-on-face therapy creates an environment which may optimize the breathing conditions of terminally-ill cancer patients. ${ }^{20}$ Lastly, because of its uncomplicated nature, fanon-face therapy is generally safe, and gives patients and their caregivers the opportunity to actively and effectively manage dyspnea during the end of life. 


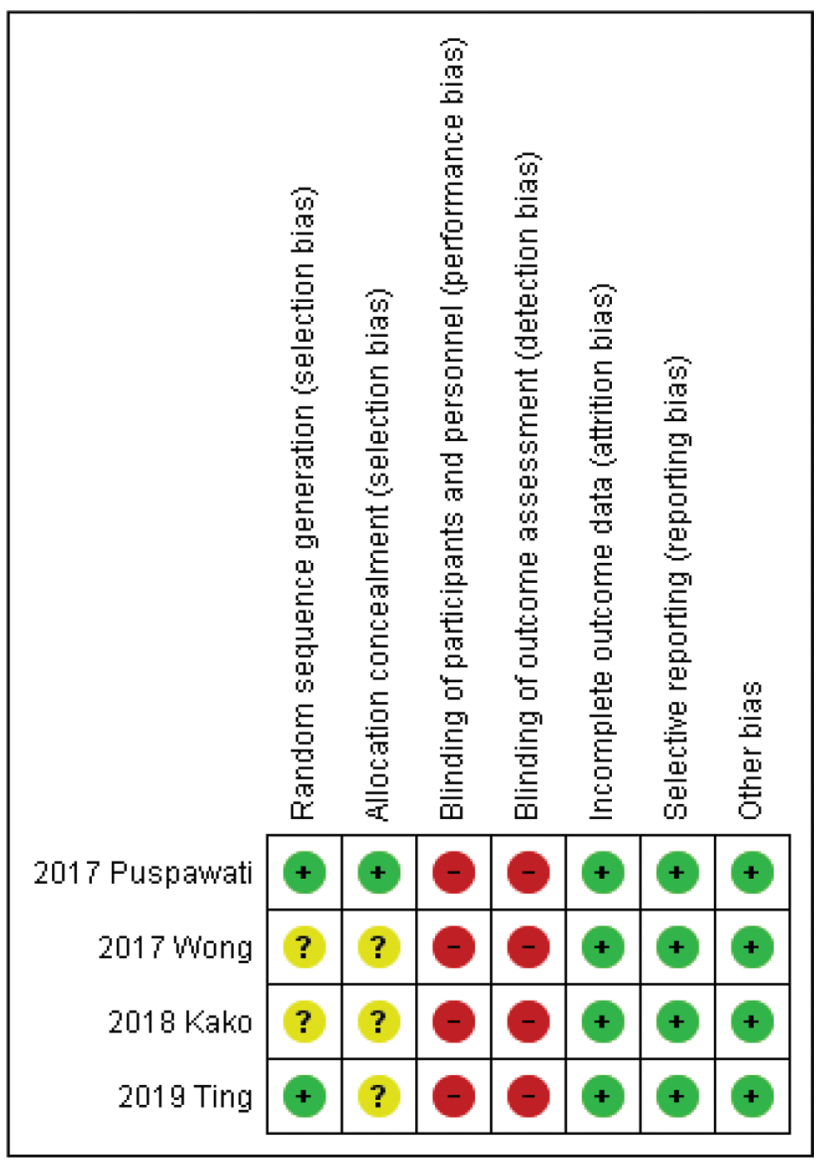

Fig. 2 Risk of bias summary.

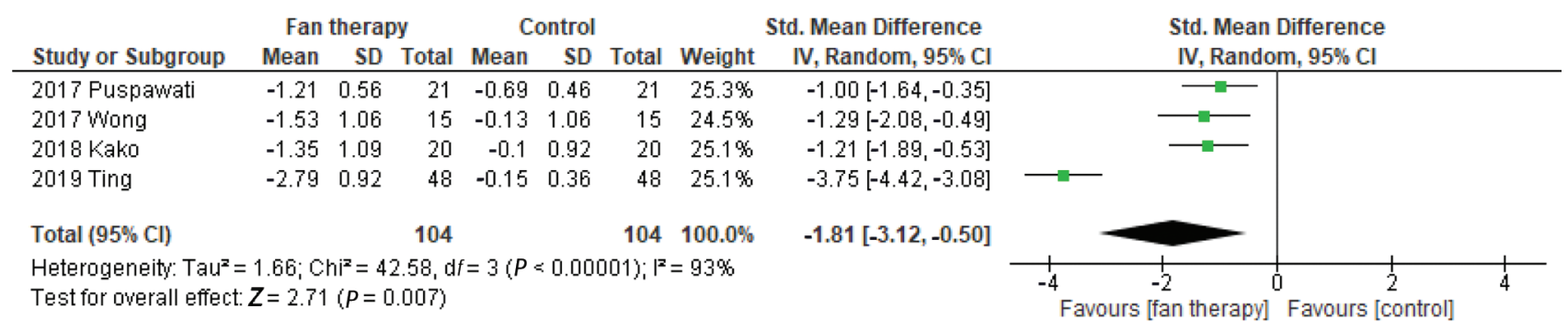

Fig. 3 Forest plot of comparison: mean change in dyspnea score.

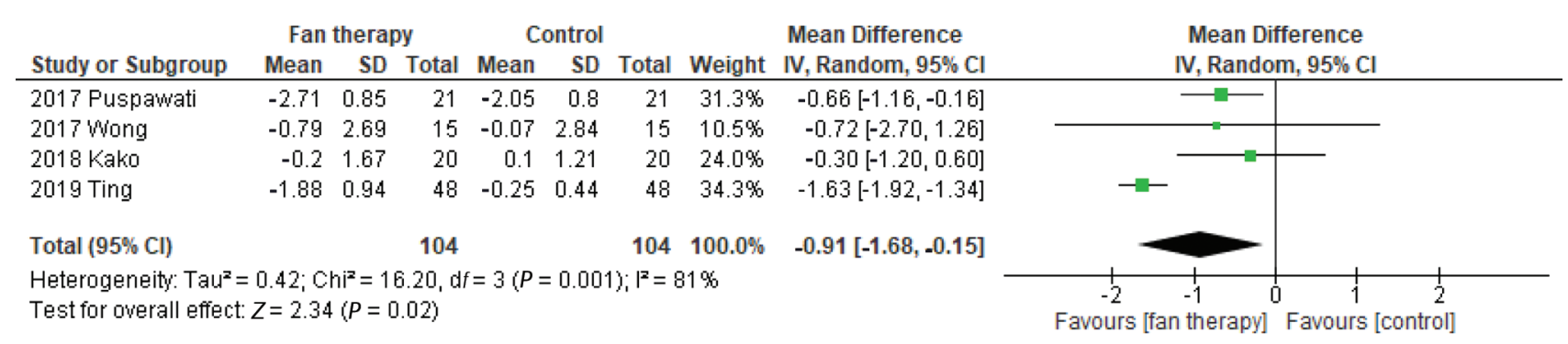

Fig. 4 Forest plot of comparison: mean change in respiratory rate. 


\section{Authors' Contributions}

M.J.L.M., F.I.L.T., J.P.B.V., D.B.L.S., and J.S.T. contributed to the analysis of data. All authors were involved during all the stages of the manuscript development.

\section{Funding}

None.

\section{Conflict of Interest}

None declared.

\section{References}

1 Kloke M, Cherny N; ESMO Guidelines Committee. Treatment of dyspnoea in advanced cancer patients: ESMO Clinical Practice Guidelines. Ann Oncol 2015;26(suppl 5):v169-v173

2 Viola R, Kiteley C, Lloyd NS, Mackay JA, Wilson J, Wong RK; Supportive Care Guidelines Group of the Cancer Care Ontario Program in Evidence-Based Care. The management of dyspnea in cancer patients: a systematic review. Support Care Cancer 2008;16(4):329-337

3 Ekström MP, Abernethy AP, Currow DC. The management of chronic breathlessness in patients with advanced and terminal illness. BMJ 2015;350:g7617

4 Zhao I, Yates P. Non-pharmacological interventions for breathlessness management in patients with lung cancer: a systematic review. Palliat Med 2008;22(6):693-701

5 Bausewein C, Booth S, Gysels M, Higginson I. Nonpharmacological interventions for breathlessness in advanced stages of malignant and non-malignant diseases. Cochrane Database Syst Rev 2008;(2):CD005623

6 Booth S, Moffat C, Burkin J, Galbraith S, Bausewein C. Nonpharmacological interventions for breathlessness. Curr Opin Support Palliat Care 2011;5(2):77-86

7 Galbraith S, Fagan P, Perkins P, Lynch A, Booth S. Does the use of a handheld fan improve chronic dyspnea? A randomized, controlled, crossover trial. J Pain Symptom Manage 2010;39(5):831-838

8 Bausewein C, Booth S, Gysels M, Kühnbach R, Higginson IJ. Effectiveness of a hand-held fan for breathlessness: a randomised phase II trial. BMC Palliat Care 2010;9:22

9 Kako J, Kobayashi M, Oosono Y, Kajiwara K, Miyashita M. Immediate effect of fan therapy in terminal cancer with dyspnea at rest: a meta-analysis. Am J Hosp Palliat Care 2020;37(4):294-299

10 Puspawati NLPD, Sitorus R, Herawati T. Hand-held fan airflow stimulation relieves dyspnea in lung cancer patients. Asia Pac J Oncol Nurs 2017;4(2):162-167

11 Ting FIL, Estreller S, Strebel HMJ. The FAFA Trial: A phase 2 randomized clinical trial on the effect of a fan blowing air on the face to relieve dyspnea in filipino patients with terminal cancer. Asian J Oncol 2020;6:3-9

12 Kako J, Morita T, Yamaguchi T, et al. Fan therapy is effective in relieving dyspnea in patients with terminally Ill cancer: a parallel-arm, randomized controlled trial. J Pain Symptom Manage 2018;56(4):493-500

13 Johnson MJ, Bland JM, Oxberry SG, Abernethy AP, Currow DC. Clinically important differences in the intensity of chronic refractory breathlessness. J Pain Symptom Manage 2013;46(6):957-963

14 Hui D, Shamieh O, Paiva CE, et al. Minimal clinically important difference in the physical, emotional, and total symptom distress scores of the Edmonton symptom assessment system. J Pain Symptom Manage 2016;51(2):262-269

15 NCCN Clinical Practice Guidelines in Oncology. Palliative care (version 2. 2019). Available at: https://www.nccn.org/professionals/physician_gls/pdf/palliative.pdf. Accessed September 12, 2019

16 Simon PM, Basner RC, Weinberger SE, Fencl V, Weiss JW, Schwartzstein RM. Oral mucosal stimulation modulates intensity of breathlessness induced in normal subjects. Am Rev Respir Dis 1991;144(2):419-422

17 Schwartzstein RM, Lahive K, Pope A, Weinberger SE, Weiss JW. Cold facial stimulation reduces breathlessness induced in normal subjects. Am Rev Respir Dis 1987;136(1):58-61

18 Burgess KR, Whitelaw WA. Effects of nasal cold receptors on pattern of breathing.J Appl Physiol (1985) 1988;64(1):371-376

19 Peiffer C. Morphine-induced relief of dyspnea: what are the mechanisms? Am J Respir Crit Care Med 2011;184(8):867-869

20 Booth S, Galbraith S, Ryan R, Parker RA, Johnson M. The importance of the feasibility study: lessons from a study of the handheld fan used to relieve dyspnea in people who are breathless at rest. Palliat Med 2016;30(5):504-509

21 Wong SL, Leong SM, Chan CM, Kan SP, Cheng HW. the effect of using an electric fan on dyspnea in Chinese patients with terminal cancer. Am J Hosp Palliat Care 2017;34(1):42-46 